\title{
Research Article \\ Effective Methane Extraction Radius after High-Pressure Water Jet Slotting
}

\author{
Hu Ke $\mathbb{D}^{1}{ }^{1}$ Xia Binwei, ${ }^{2,3}$ Liu Chengwei, $^{4}$ and Lu Yiyu ${ }^{2,3}$ \\ ${ }^{1}$ Institute of Mining and Special Civil Engineering, TU Bergakademie Freiberg, 09599, Freiberg, Germany \\ ${ }^{2}$ State Key Laboratory of Coal Mine Disaster Dynamics and Control, Chongqing University, Chongqing 400044, China \\ ${ }^{3}$ School of Resources and Safety Engineering, Chongqing University, Chongqing 400044, China \\ ${ }^{4}$ School of Mines and Civil Engineering, Liupanshui Normal University, Liupanshui 553004, China
}

Correspondence should be addressed to Hu Ke; ke.hu@student.tu-freiberg.de

Received 8 May 2020; Revised 31 May 2020; Accepted 4 June 2020; Published 1 August 2020

Academic Editor: Zhengyang Song

Copyright (c) $2020 \mathrm{Hu} \mathrm{Ke}$ et al. This is an open access article distributed under the Creative Commons Attribution License, which permits unrestricted use, distribution, and reproduction in any medium, provided the original work is properly cited.

\begin{abstract}
The effective radius of methane extraction after high-pressure water jet slotting is the most important parameter for borehole optimization and extraction time planning. We applied a steady flow model and thermal-hydrological-mechanical (THM) coupling model to calculate the effective radius after high-pressure water jet slotting. Field measurements at the Zhongliangshan coal mine show that both the steady flow model and the THM coupling model can accurately represent the effective radius, and the THM coupling model provides further information regarding extraction time. After that, a variety of factors, including extraction time, coal burial depth, slot radius, initial permeability, and initial methane pressure, are discussed. The effective radius of a slotted borehole is 1.94 times larger than that of a conventional borehole.
\end{abstract}

\section{Introduction}

Coalbed methane (CBM) extraction is an intensive method for reducing the security risk of coal and methane outbursts during mine production [1] that can provide cleaner energy resources [2] and potentially reduce greenhouse gas emissions [3]. CBM is mainly composed of methane (CH4), which has a greenhouse effect that is $\sim 25$ times stronger than that of carbon dioxide [4].

The CBM in China ranks third in the world with 3.68 $\times 10^{12} \mathrm{~m}^{3}$ of reserves at depths $<2000 \mathrm{~m}$ [5]. The total potential CBM includes considerable amounts of onshore conventional natural gas resources and provided 7.26 billion $\mathrm{m}^{3}$ of energy in 2018 [6]. The target for underground CBM production in China is 14 billion $\mathrm{m}^{3}$ in 2020 , according to the $13^{\text {th }}$ five-year plan of the Development and Utilization of Coalbed Methane [7]. Preextraction of CBM can reduce the risk of methane explosion [8-11] as well as coal and gas outburst.
The permeability of most Chinese coal seams is $<1 \mathrm{mD}$, in which $35 \%$ have $<0.1 \mathrm{mD}$ and $37 \%$ are tight with permeabilities ranging between 0.1 and $1 \mathrm{mD}$ [1]. Drainage of coal seams with permeability $<1 \mathrm{mD}$ is difficult according to the Coal Bed Methane Drainage Engineering Design Specification (GB50471-2008). For coal seams with extremely low permeability and low porosity, conventional extraction methods that involve drilling in coal seams from underground or at the surface are inefficient, costly, and timeconsuming. Several methods have been proposed to improve the efficiency of CBM extraction.

High-pressure water jet slotting [12-16] has been widely applied to enhance CBM extraction from underground coal seams with extremely low permeability, as shown in Figure 1. The coal seams may undergo tensile, compressive, or shear failure under the dynamic loading of the highpressure water jet $[15,17,18]$, which can enhance intrinsic cracks and propagate new cracks. Discoid caves can reduce the effective stress in coal seams and exponentially increase 


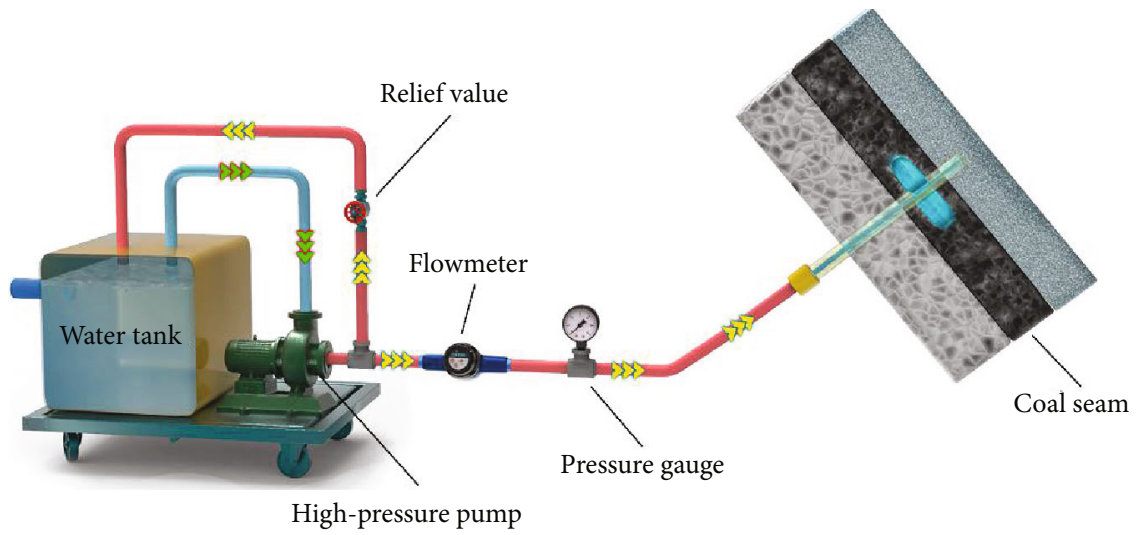

FIgURE 1: The schematic diagram of the high-pressure water jet system in the coal seam.

their permeability $[19,20]$. A higher concentration of adsorbed methane can desorb from the enhanced coal seam surface after being slotted by a high-pressure water jet [21].

The most important parameter to consider during this process is the effective methane extraction radius after high-pressure water jet slotting, which has been determined empirically. A methane pressure of $0.74 \mathrm{MPa}$ was set as the coal and gas outburst risk criterion according to the Specification of Coal and Gas Outburst Prevention [22]. This pressure eliminates hazards related to coal and gas outburst hazards and allows safe mining operations. The influence radius is generally considered that under which the range of methane pressure loss is $10 \%$ [23], whereas areas with pressure $<0.74 \mathrm{MPa}$ are considered the effective methane extraction radius. The latter is clearly more advantageous for optimizing field applications and is therefore an important focus of the study.

An effective radius of methane execration is a crucial parameter for the layout of drilling boreholes and the extracting plan. Exceedingly large spacing between boreholes tends to allow the emergence of blind spots in the coal seams with insufficient extraction and may lead to coal and gas outburst accidents during production. In contrast, if borehole spacing is too small, leakage can occur and more boreholes must be drilled, which is wasteful and inefficient.

With the increasing demand for coal, mining operations have descended to increasingly deeper depths at a rate of $20 \mathrm{~m} / \mathrm{yr}$ [24]. The effects of temperature for methane adsorption/desorption, methane flow, and coal seam deformation are more prominent with increasing mining depth. Additionally, the distribution of stress and flow pattern of methane around discoid caves differs considerably from transitional cylinder boreholes. Most importantly, the techniques used to establish the effective radius of methane extraction from the traditional boreholes are invalid for deep boreholes.

To provide improved guidance for methane extraction, we propose an efficient and robust method within a thermal-hydrological-mechanical (THM) coupling model to calculate the effective radius of methane extraction after high-pressure water jet slotting. We applied theoretical analysis, numerical simulations, model validation, and sensitivity analysis to detect the methane distribution after slotting.

\section{Methodology}

2.1. Steady Methane Flow Model. When a discoid cave is slotted by a water jet, methane molecules desorb from the coal surface and flow through the borehole. The methane flow areas around the hole can be divided into three zones (Figure 2): a linear seepage zone, a low-speed nonlinear seepage zone, and a diffusion zone. The diffusion coefficient of methane in coal seams is extremely low, and the contribution of methane diffusion can be ignored for low-permeability coal seams [25].

According to Darcy's law, the velocity of methane flow in the linear seepage zone can be expressed as [26]

$$
V=10^{-3} \frac{k \Delta P}{\mu L_{1}},
$$

where $V$ is the methane seepage velocity $(\mathrm{m} / \mathrm{s}), k$ is the coal seam permeability $\left(\mu \mathrm{m}^{2}\right), \mu$ is the dynamic viscosity of methane (mPa.s), $\Delta P$ is the pressure difference $(\mathrm{MPa})$, and $L_{1}$ is the maximum methane migration distance in the linear seepage zone $(\mathrm{m})$.

The Reynolds number ( $\mathrm{Re})$ has been recognized as the determining criterion for fluid flow patterns, and $\mathrm{Re}=10^{-4}$ represents the boundary between linear and nonlinear seepage [27]:

$$
\operatorname{Re}=10^{-4} \frac{v \sqrt{k} \rho}{17.50 \mu \phi^{3 / 2}},
$$

where $\rho$ is the density of the methane $\left(\mathrm{g} / \mathrm{cm}^{3}\right)$ and $\phi$ is the porosity. By substituting Equation (1) into Equation (2), $L_{1}$ can be expressed as

$$
L_{1}=\frac{10^{-15} \rho \Delta P k^{3 / 2}}{17.5 u^{2} \phi^{3 / 2} \mathrm{Re}}
$$

When flowing in a low-permeability coal seam, methane molecules collide against coal pore walls because the pore diameters are smaller than the mean free path. On a macrolevel, this collision is called a slippage effect and is conditional 


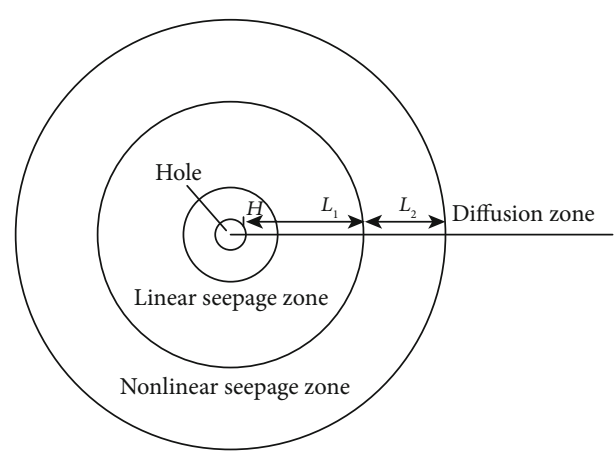

Figure 2: Steady methane flow field area around a discoid cave where $H$ is the cave radius and $L_{1}$ and $L_{2}$ are the maximum distance for methane movement in the linear seepage zone and nonlinear seepage zone, respectively.

because of the starting pressure gradient $\left(\lambda_{B}\right)$ when methane flows at a lower velocity. When the pressure gradient exceeds $\lambda_{B}$, the methane flow is predominantly low-speed nonlinear seepage; when the pressure gradient is less than $\lambda_{B}$, methane flow is only governed by diffusion. According to the lowspeed nonlinear seepage law, it can be concluded that

$$
V= \begin{cases}\frac{k}{\mu}\left(1+\frac{2 B}{P_{1}+P_{2}}\right) \frac{\Delta P}{L}, & \frac{\Delta P}{L}>\lambda B, \\ 0, & \frac{\Delta P}{L} \leq \lambda B,\end{cases}
$$

where $P_{1}$ and $P_{2}$ represent the methane pressure of the inflow and outflow sides, respectively, and $B$ is the Klinkenberg coefficient.

The relationship between $\lambda_{B}$ and coal seam permeability can be expressed as [28]

$$
\lambda_{B}=0.0113 k^{-0.33034} \text {, }
$$

when $V=0$ in Equation (1) and $L_{2}$ represents the maximum distance of methane movement within the nonlinear seepage zone, thus

$$
L_{2}=\frac{\Delta P}{\lambda_{B}}
$$

The maximum radius of methane extraction can therefore be expressed as

$$
R=H+L_{1}+L_{2}=H+\frac{10^{-15} \rho \Delta P k^{3 / 2}}{17.5 \mu^{2} \phi^{3 / 2} \operatorname{Re}}+\frac{\Delta P}{\lambda_{B}},
$$

where $H$ represents the cave radius. In Equation (7), $H+L_{1}$ can be thought of as the effective radius and $R$ as the influence radius. Equation (7) provides a time-independent solution of the effective radius and influence radius, but the extraction time remains unknown and the effect of temperature in methane extraction is ignored.

2.2. The THM Coupling Model for Methane Flow. The THM coupling model directly evaluates the effective radius of methane extraction as well as the extraction time [29]. To establish the THM coupling model for methane extraction after high-pressure water jet slotting, we suggest the following basic assumptions [30-32]: (1) the coal seams are homogeneous and isotropic porous media; (2) the deformation of coal skeleton and porosity is minimal and can be described by the linear elasticity criterion; (3) thermodynamic parameters of coal seams and methane are temperature independent; (4) the coal seams are saturated by methane; (5) methane adsorption on coal can be represented by the Langmuir model, and the free methane is an ideal gas.

2.2.1. Governing Equations of Coal Deformation. During methane extraction after high-pressure water jet slotting, the coal seams will deform under the influence of temperature, methane pressure, and strata pressure. The coal seam strain is the sum of strains induced by effective stress, methane adsorption-induced strain, and thermal strain. The thermal strain can be expressed as

$$
\varepsilon_{T}=\frac{1}{3} \alpha_{S} \Delta T \delta_{i j}
$$

where $\alpha_{s}$ is the coefficient of the thermal expansion $\left(\mathrm{cm}^{3} /\left(\mathrm{m}^{3} \cdot \mathrm{K}\right)\right), \Delta T$ represents the change of absolute coal seam temperature $(\mathrm{K})$, and $\delta_{i j}$ is the Kronecker symbol.

Considering the strain induced by methane adsorption, we assume that adsorption only induces volume strain and that the coal seam is isotropic. The constitutive equation of the coal seam can be drawn as follows and is negative during compression:

$$
\varepsilon_{i j}=\frac{1}{2 G} \sigma_{i j}-\left(\frac{1}{6 G}-\frac{1}{9 K}\right) \sigma_{k k} \delta_{i j}+\frac{\alpha}{3 K} p \delta_{i j}+\frac{\varepsilon_{s}}{3} \delta_{i j}
$$

where $G$ is the coal seam shear modulus (GPa), $K$ is the coal seam volume modulus $(\mathrm{GPa}), \alpha$ is the Biot effective stress coefficient, where $\alpha=1-K / K_{s}$ and $K_{s}$ and is the volume modulus of the skeleton of coal $(\mathrm{GPa}), \sigma_{k k}$ is the normal stress component $\left(\sigma_{k k}=\sigma_{11}+\sigma_{22}+\sigma_{33}\right), \varepsilon_{i j}$ is the coal strain tensor component, and $\varepsilon_{s}$ is the adsorption-induced strain.

Combining Equations (8) and (9), the constitutive equation that considers strata stress, methane pressure, adsorption-induced strain, and temperature can be expressed as [33] 
$\varepsilon_{i j}=\frac{1}{2 G} \sigma_{i j}-\left(\frac{1}{6 G}-\frac{1}{9 K}\right) \sigma_{k k} \delta_{i j}+\frac{\alpha}{3 K} p \delta_{i j}+\frac{\varepsilon_{s}}{3} \delta_{i j}+\frac{\alpha_{s} \Delta T}{3} \delta_{i j}$

The first term on the right side of Equation (10) represents the strain of the strata stress; the second term implies the strain of methane pressure. The third and fourth terms are the strain induced by adsorption and temperature, respectively.

The stress displacement equations of the coal seam are

$$
\varepsilon_{i j}=\frac{1}{2}\left(u_{i, j}+u_{j, i}\right)
$$

where $u_{i j}$ is the coal seam displacement component. The equilibrium equation for the coal seam can be expressed as

$$
\sigma_{i j, j}+f_{i}=0
$$

where $f_{i}$ is the volumetric component of the coal seam.

By combining Equations (10)-(12), the governing equation for coal seam displacement under the effects of stress, strain, methane pressure, and temperature is

$$
G u_{i, k k}+\frac{G}{1-2 v} u_{k, k i}-\alpha_{s} K T_{i}-\alpha p_{i}-K \varepsilon_{s, i}+f_{i}=0 .
$$

2.2.2. Governing Equations of Methane Flow. Assuming methane as an ideal gas, the density of methane can be described as

$$
\rho_{g}=\beta P=\frac{M P}{R_{0} T}
$$

where $\beta$ is the compressibility coefficient $\left(\mathrm{kg} /\left(\mathrm{m}^{3} \cdot \mathrm{Pa}\right)\right), \rho_{g}$ is the methane density $\left(\mathrm{kg} / \mathrm{m}^{3}\right), M$ is the molar mass of methane ( $16 \mathrm{~g} / \mathrm{mol}), R_{0}$ is the ideal gas constant $\left(8314 \mathrm{~m}^{2} /\left(\mathrm{s}^{2} \cdot \mathrm{K}\right)\right)$, and $T$ is the temperature $(\mathrm{K})$.

According to the equations of state for an ideal gas, the free methane in coal cracks, fractures, and pores can be characterized as

$$
C_{f}=\frac{\phi \rho_{g} P}{p_{n}}
$$

where $C_{f}$ is the free methane per cubic meter of coal $\left(\mathrm{kg} / \mathrm{m}^{3}\right)$ and $p_{n}$ is the atmospheric pressure $(0.1 \mathrm{MPa})$.

The Langmuir model is widely used for representing methane adsorption on coal and can be expressed as [34]

$$
Q_{x}=\rho_{c} \rho_{g} \frac{a b P}{1+b P}
$$

where $Q_{x}$ is the mass of adsorbed methane per cubic meter of coal $\left(\mathrm{kg} / \mathrm{m}^{3}\right), a$ is the maximum monolayer adsorption capacity $\left(\mathrm{m}^{3} / \mathrm{t}\right)$, and $b$ is the Langmuir pressure, which represents the pressure when the adsorbed methane equals $50 \%$ of its maximum quantity $(\mathrm{MPa})$.
Methane adsorption is an exothermic process, and the relationship between temperature and the Langmuir parameter is described in the literature as [35]

$$
\left\{\begin{array}{l}
a=-0.0031 T^{2}+0.2297 T+26.841 \\
b=-0.0157 T+1.6798
\end{array}\right.
$$

Combining Equations (15), (16), and (17), the methane content is the sum of the free methane and adsorbed methane and can be described as

$$
Q=C_{f}+Q_{x}=\frac{\phi \rho_{g} P}{p_{n}}+\rho_{c} \rho_{g} \frac{a b P}{1+b P}
$$

where $Q$ is the methane content for a unit volume of coal, $\mathrm{kg} / \mathrm{m}^{3}$. According to Darcy's law and the conservation of mass,

$$
\frac{\partial Q}{\partial t}+\nabla \cdot\left(\rho_{g} q\right)=I
$$

where $I$ is the mass source term.

At an increased mining depth, the effect of temperature on the dynamic viscosity of methane can be ignored, and the dynamic viscosity of methane is set to $\mu=1.08 \times 10^{-5}$ $\mathrm{Pa} \cdot \mathrm{s}$. We then obtain the governing equation for methane flow under nonisothermal conditions:

$$
\begin{gathered}
\frac{(1-\phi) a b M \rho_{s}}{R_{0} T}\left[\frac{4 P^{2}-b P^{2}}{(1+b P)^{2}}\right] \frac{\partial p}{\partial t}-\frac{a b P^{2} M \rho_{s}}{(1+b P) R_{0} T} \frac{\partial \phi}{\partial t} \\
\left.-\frac{(1-\phi) a b P^{2} M \rho_{s} \frac{\partial T}{\partial t}-\nabla\left(\frac{k}{\mu} \nabla P^{2}\right)=0 .}{(1+b P) R_{0} T^{2}} \frac{\partial}{\partial t}\right)
\end{gathered}
$$

2.2.3. Governing Equations of the Temperature Field. There are three types of thermal transmission in coal seams: heat exchange, thermal radiation, and thermal convection. Because the effect of thermal radiation is negligible and methane adsorption is an endothermic process, heat transfer in a coal seam can be simplified to unsteady thermal conduction in three dimensions with an internal heat source. According to the conversation of energy, we obtain [36]

$$
\begin{aligned}
& \frac{\partial\left(\rho_{s} c_{s} \Delta T+\phi \rho_{g} c_{g} \Delta T\right)}{\partial t}+T \alpha_{s} K \frac{\partial \varepsilon_{v}}{\partial t}+q_{s t} Q_{x} \\
& +\nabla \cdot \rho_{g} h_{g} q_{g}+\nabla \cdot\left(k_{t} \nabla T\right)=Q_{T},
\end{aligned}
$$

where $c_{s}$ is the specific heat capacity of the coal seam $(\mathrm{J} /(\mathrm{K} \cdot \mathrm{kg})), c_{g}$ is the specific heat capacity of methane $(\mathrm{J} /(\mathrm{K} \cdot \mathrm{kg})), h_{g}$ is the specific enthalpy of methane $(\mathrm{kJ} / \mathrm{mol})$, $q_{s t}$ is the isosteric heat of methane $(33.4 \mathrm{~kJ} / \mathrm{mol})$ [37], and $k_{t}$ is the weighted thermal conductivity for methane and coal. 


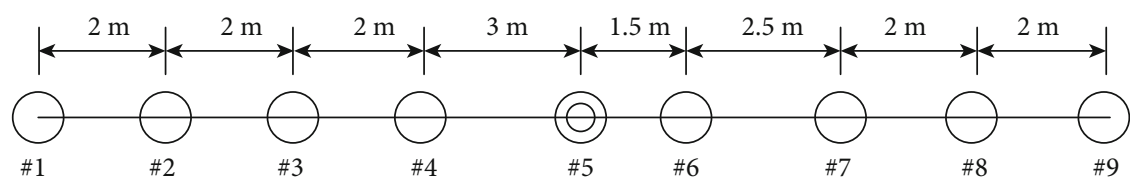

FIGURE 3: Schematic diagram of the boreholes.

2.2.4. Coupled Governing Equations. According to the definition of the porosity,

$$
\phi=\frac{V_{P}}{V_{B}}=1-\frac{1-\phi_{0}}{1+\varepsilon_{V}}\left(1+\frac{\Delta V_{s}}{V_{s 0}}\right),
$$

where $V_{s 0}$ is the initial volume of the coal seam skeleton $\left(\mathrm{m}^{3}\right)$, $\Delta V_{s}$ is the volume increment of the skeleton $\left(\mathrm{m}^{3}\right), V_{P}$ is the total pore volume $\left(\mathrm{m}^{3}\right), V_{B}$ is the total coal volume $\left(\mathrm{m}^{3}\right), \phi_{0}$ is the initial coal porosity of coal, and $\varepsilon_{V}$ is the volume strain of the coal.

When the coal skeleton is affected by pore pressure, temperature, and adsorption-induced swelling, the volume change of the coal skeleton can be described as

$$
\frac{\Delta V_{s}}{V_{s 0}}=\alpha_{s} \Delta T-K_{Y} \Delta p+\frac{\varepsilon_{s}}{1-\phi_{0}},
$$

where $K_{Y}$ is the compression factor of coal, $K_{Y}=1 / K_{S}=$ $3(1-2 v) / E$, where $v$ is Poisson's ratio.

The methane adsorption-induced swelling strain of coal can be expressed as [38]

$$
\varepsilon_{s}=\frac{2 \rho_{s} R_{0} T a \ln (1+b P)}{9 V_{m} K},
$$

where $K$ is the bulk modulus of the coal $(\mathrm{GPa})$ and $V_{m}$ is the molar volume of methane $(22.4 \mathrm{~L} / \mathrm{mol})$. According to Equations (22)-(24), the dynamic evolution model of porosity can be achieved:

$\phi=\frac{\varepsilon_{v}+\phi_{0}}{1+\varepsilon_{v}}\left[1+\alpha_{s} \Delta T-\frac{3 \Delta P(1-2 v)}{E}+\frac{2 a \rho_{s} R_{0} T \ln (1+b P)}{9\left(1-\phi_{0}\right) V_{m} K}\right]$.

The Kozeny-Carman equation establishes the relationship between porosity and permeability:
TAble 1: Parameters for the THM coupling model.

\begin{tabular}{lc}
\hline Parameter & Value \\
\hline Overburden pressure & $14.4 \mathrm{MPa}$ \\
Elastic modulus, $E$ & $4.06 \times 10^{9} \mathrm{~Pa}[41]$ \\
Poisson's ratio, $v$ & $0.28[42]$ \\
Thermal expansion coefficient, $\alpha_{s}$ & $1.16 \times 10^{-5} \mathrm{~m}^{3} /\left(\mathrm{m}^{3} \cdot \mathrm{K}\right)[43]$ \\
Methane viscosity, $\mu$ & $1.08 \times 10^{-5} \mathrm{~Pa} \cdot \mathrm{s}$ \\
Coal density, $\rho_{s}$ & $1400 \mathrm{~kg} / \mathrm{m}^{3}$ \\
Initial porosity, $\Phi_{0}$ & 0.062 \\
Initial permeability, $k_{0}$ & $0.025 \mathrm{mD}$ \\
Initial methane pressure, $P_{0}$ & $2.0 \mathrm{MPa}$ \\
Specific heat capacity of coal, $c_{s}$ & $4186 \mathrm{~J} /(\mathrm{kg} \cdot \mathrm{K})[44]$ \\
Specific heat capacity of methane, $c_{g}$ & $2227 \mathrm{~J} /(\mathrm{kg} \cdot \mathrm{K})$ \\
\hline
\end{tabular}

$$
k=\frac{\phi V_{P}^{2}}{K_{z} A_{S}{ }^{2}},
$$

where $K_{z}$ is the Kozeny constant, $V_{p}$ is the specific surface area of the unit volume $\left(\mathrm{cm}^{2}\right)$, and $A_{S}$ is the specific surface area $\left(\mathrm{cm}^{2}\right)$.

Substituting Equation (25) into Equation (26), we obtain the dynamic evolution model of coal permeability using the THM coupling model:

$$
\begin{aligned}
k= & \frac{k_{0}}{\exp \left(-K_{Y} \Delta \sigma^{\prime}\right)}\left[1+\frac{\varepsilon_{v}}{\phi_{0}}-\frac{\left(\alpha_{s} \Delta T-K_{Y} \Delta P\right)\left(1-\phi_{0}\right)}{\phi_{0}}\right. \\
& \left.-\frac{2 \rho_{s} R_{0} T a \ln (1+b P)}{9 \phi_{0} V_{m} K}\right]^{3},
\end{aligned}
$$

where $\Delta \sigma^{\prime}$ is the variation of the effective stress (MPa).

The THM coupling model for methane extraction after high-pressure water jet slotting can therefore be summarized as

$$
\left\{\begin{array}{l}
G u_{i, k k}+G u_{i, k k}+\frac{G}{1-2 v} u_{k, k i}-\alpha_{s} K T_{i}-\alpha p_{i}-K \varepsilon_{s, i}+f_{i}=0, \\
\frac{(1-\phi) a b M \rho_{s}}{R_{0} T}\left[\frac{4 P^{2}-b P^{2}}{(1+b P)^{2}}\right] \frac{\partial p}{\partial t}-\frac{a b P^{2} M \rho_{s}}{(1+b P) R_{0} T} \frac{\partial \phi}{\partial t}-\frac{(1-\phi) a b P^{2} M \rho_{s} \partial T}{(1+b P) R_{0} T^{2}} \frac{\partial T}{\partial t}-\nabla\left(\frac{k}{\mu} \nabla P^{2}\right)=0, \\
\frac{\partial\left(\rho_{s} c_{s} \Delta T+\phi \rho_{g} c_{g} \Delta T\right)}{\partial t}+T \alpha_{s} K \frac{\partial \varepsilon_{v}}{\partial t}+q_{s t} Q+\nabla \cdot \rho_{g} h_{g} q_{g}+\nabla \cdot\left(k_{t} \nabla T\right)=Q_{T} .
\end{array}\right.
$$




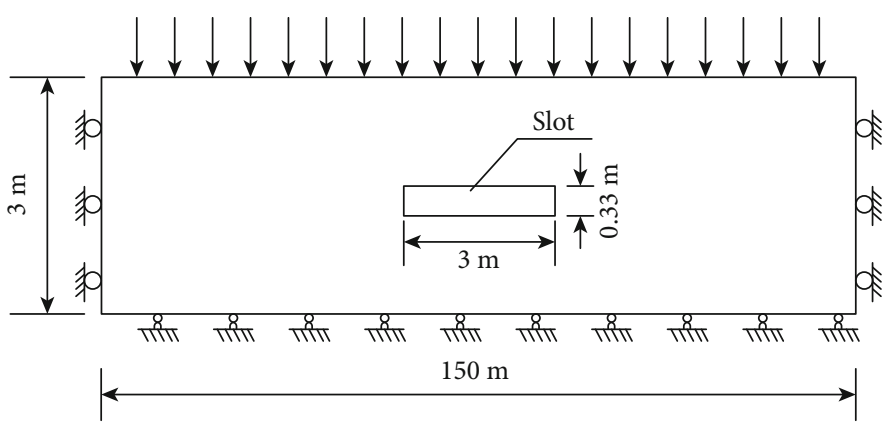

Figure 4: Schematic diagram of the calculation model.

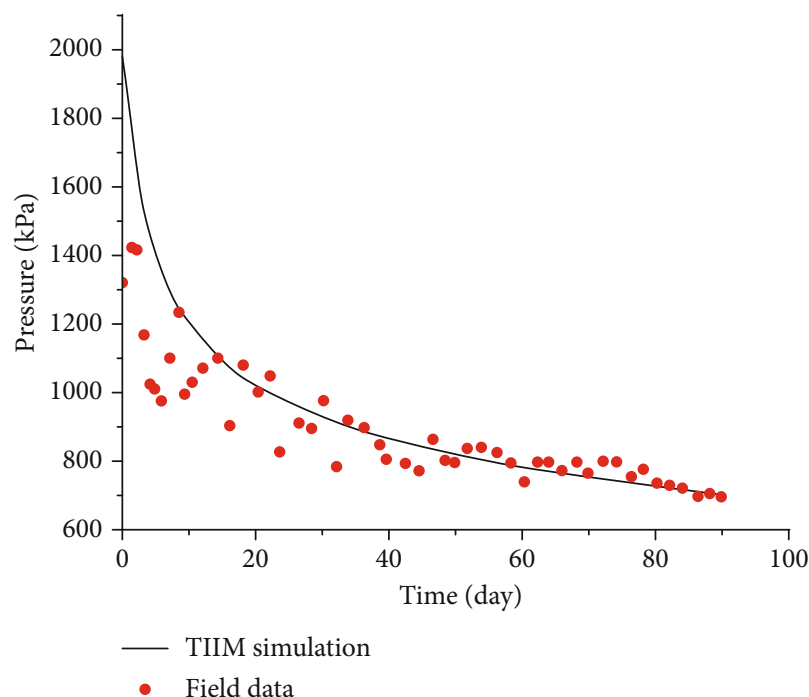

(a)

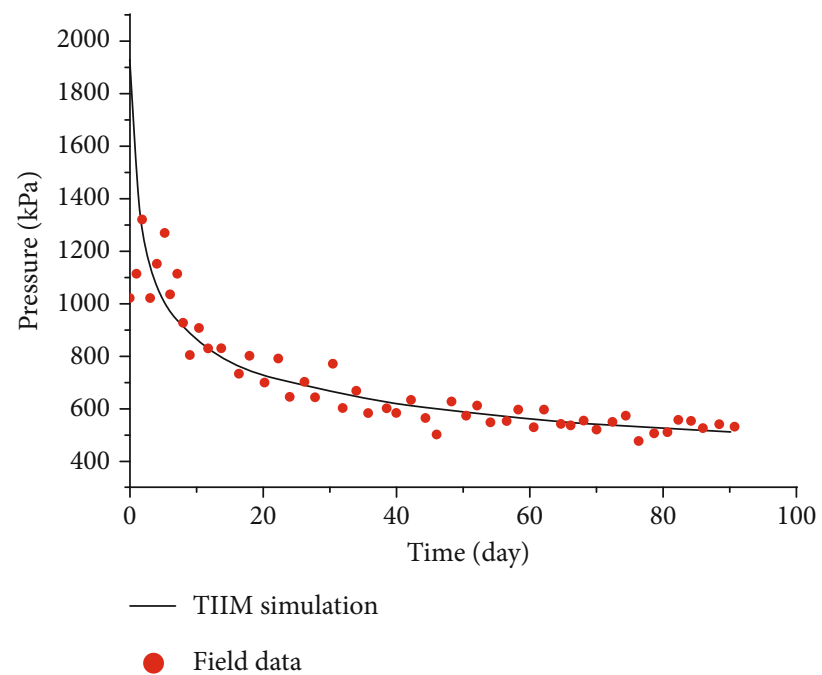

(b)

FIgURE 5: Field measurements and THM coupling model simulated methane pressures (a) for borehole \#4 and (b) borehole \#3. Red circles denote the field measured data, and solid lines represent the model simulation.

\section{Model Validation}

To validate the fully-coupled model, a field test was conducted in the K10 coal seam of the Zhongliangshan coal mine in Chongqing in southwestern China. The borehole layout for slotting and methane pressure determination is illustrated in Figure 3. Nine boreholes were drilled. Borehole \#5 was used to perform high-pressure water jet slotting, borehole \#6 was used to verify the slotting radius, and the other boreholes were used to detect the methane pressure. Slotting was stopped when water was observed in borehole \#6. The depth of the K10 coal seam in the test is $575 \mathrm{~m}$, the initial methane pressure was $1.9 \mathrm{MPa}$, the initial permeability was $1.7 \times$ $10^{-17} \mathrm{~m}^{2}$, and the negative drainage pressure in the slotted borehole was $35 \mathrm{kPa}$. All parameters are listed in Table 1 . The perfect symmetry of the coal seam and boreholes is shown as a two-dimensional model in Figure 4 and used to simulate methane extraction to simplify the calculation. The two-dimensional model is $150 \mathrm{~m}$ in length and $3 \mathrm{~m}$ in height. At the upper boundary of the model, we applied an evenly distributed normal stress according to depth. The left and right sides of the model are restrained from horizontal displacement and insulated for methane and thermal transport purposes. The bottom boundary is restrained from normal displacement and insulated for methane and thermal transport. The above governing equations and complete set of coupled equations were solved by using the PDE module of COMSOL Multiphysics [39].

The comparative plot in Figure 5 represents that the THM coupling model can perfectly fit the data from the field measurement, and Figure 6 reveals that both the steady flow model and the THM coupling model can well represent the field data of methane extraction. For boreholes \#3 and \#4, the methane pressure decreases faster than the numerical results over a relatively short time. This is mainly because the stress distribution around the slot changes owing to the slotting process. Plastic deformation may have occurred, and the coal permeability is higher than the THM coupling model prediction [40]. After compaction and stress redistribution, the methane pressures were in good agreement with the numerical results. The results determined in the field also show good consistency with the effective radius and influence radius calculated by the steady flow model (Figure 6). 


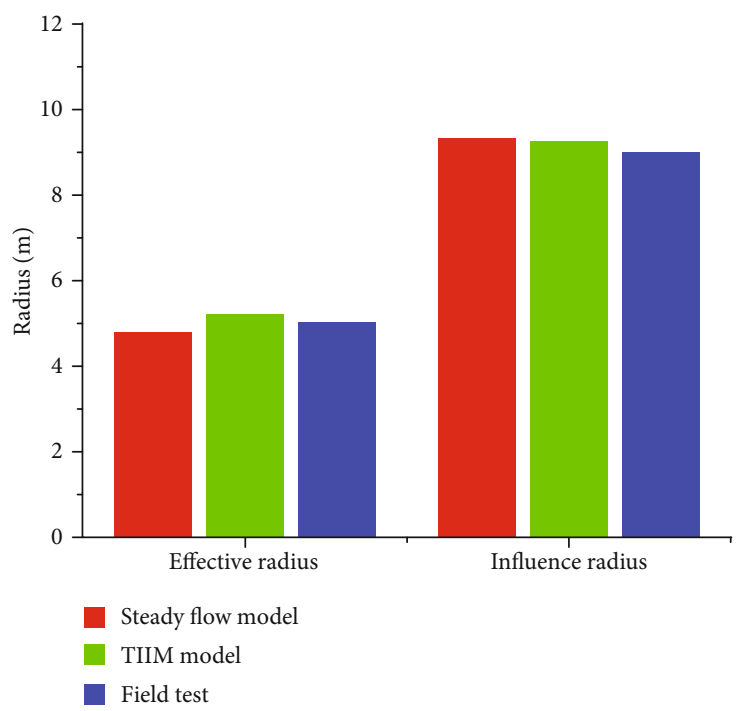

FIGURE 6: Effective radius and influence radius of methane extraction obtained from the steady flow model, THM coupling model, and field tests.

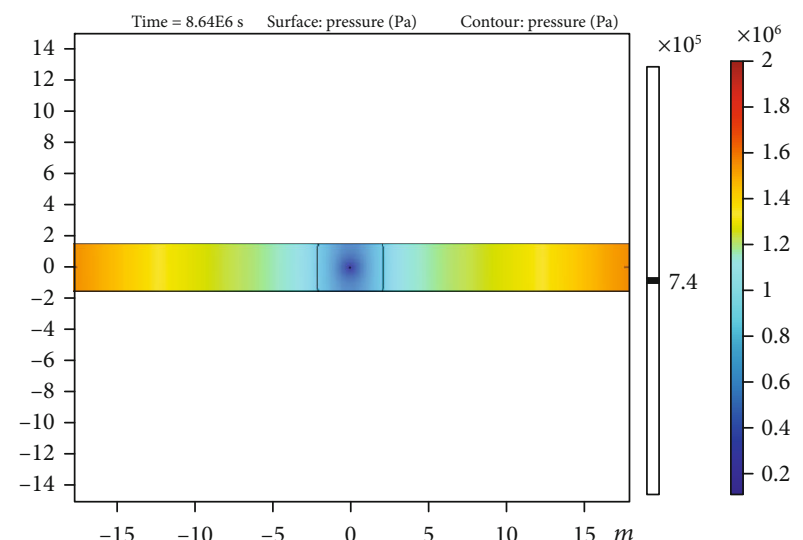

(a)

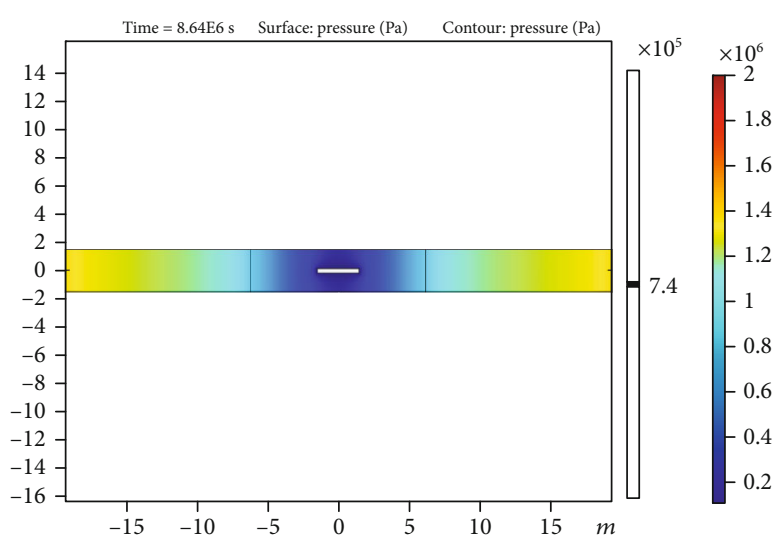

(b)

FiguRE 7: Comparison of a (a) traditional borehole and (b) slotted borehole after 100 days of extraction.

\section{Analysis of Influencing factors}

Methane flow in coal seams is controlled by a range of factors, including initial methane permeability, initial methane pressure, burial depth of coal seam, and extraction time. To better understand methane extraction after high-pressure water jet slotting, all of these factors should be analyzed based on the robust model. This provides information for optimizing borehole drilling and extraction time in practical operations in different coal seams with complicated parameters.

4.1. Comparison with a Traditional Borehole. Figure 7 shows the pressure distribution of methane for a traditional borehole with a diameter of $75 \mathrm{~mm}$ and a slotted borehole after 100 days of extraction. The black contour in Figure 7 represents $0.74 \mathrm{MPa}$. In the traditional borehole, the effective radius was $2.11 \mathrm{~m}$, whereas the effective radius for the slotted borehole was $6.2 \mathrm{~m}$. This indicates that the high-pressure water jet slotting not only increases the exposed area but can substantially enhance the effective radius of methane extraction. The drilling of slotted boreholes in coal seams can be reduced by $\sim 80 \%$ of that of traditional boreholes.

4.2. Influence of Extraction Time. Figure 8 shows the distribution of methane pressure in the coal seam after 1, 50, 300, 500, and 1000 days of extraction. The respective effective extraction radii are $1.77,4.7,9.78,10.8$, and $10.98 \mathrm{~m}$, respectively. The fitting relationship between extraction time and effective radius (Figure 9) shows that the effective radius increases rapidly from the beginning until 350 days and then increases slowly and remains nearly unchanged until 1000 days. In practical operations, the extraction time can be optimized to about 350 days.

4.3. Influence of Coal Burial Depth. To consider an actual situation of underground mining in China, we varied the coal 


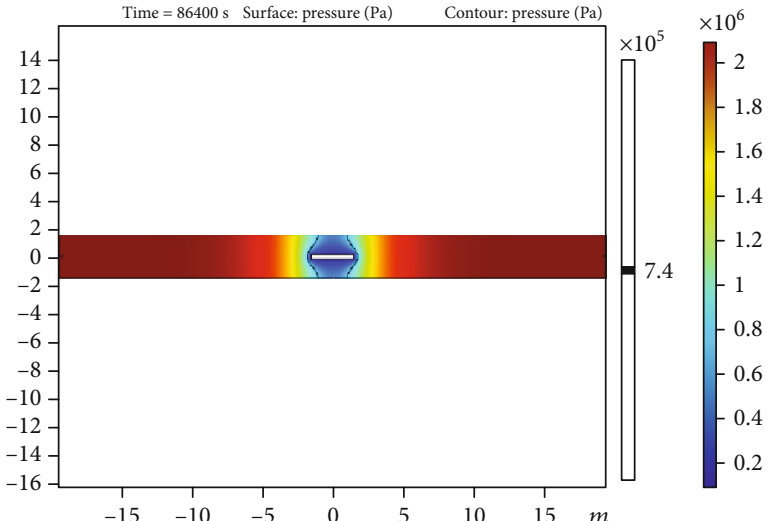

(a)

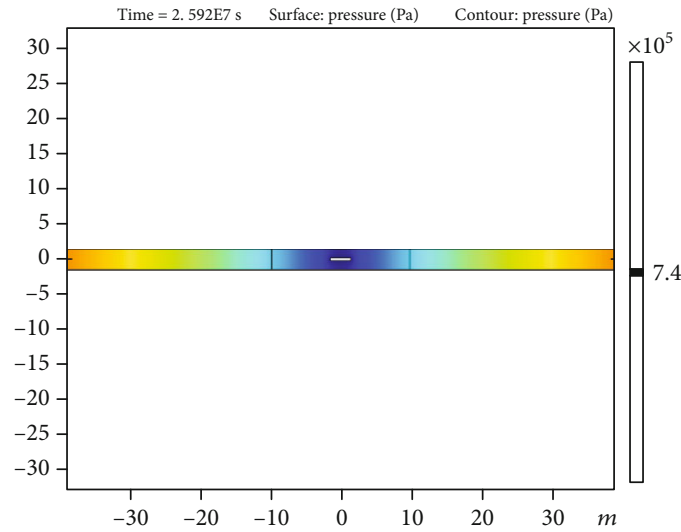

(c)

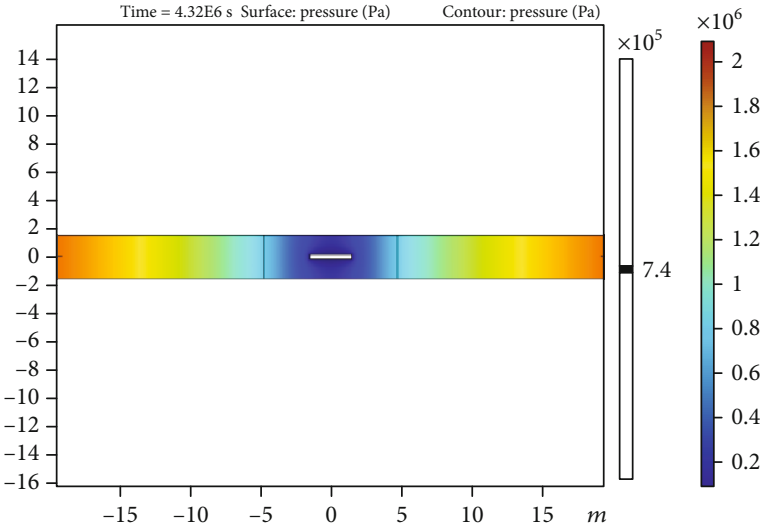

(b)

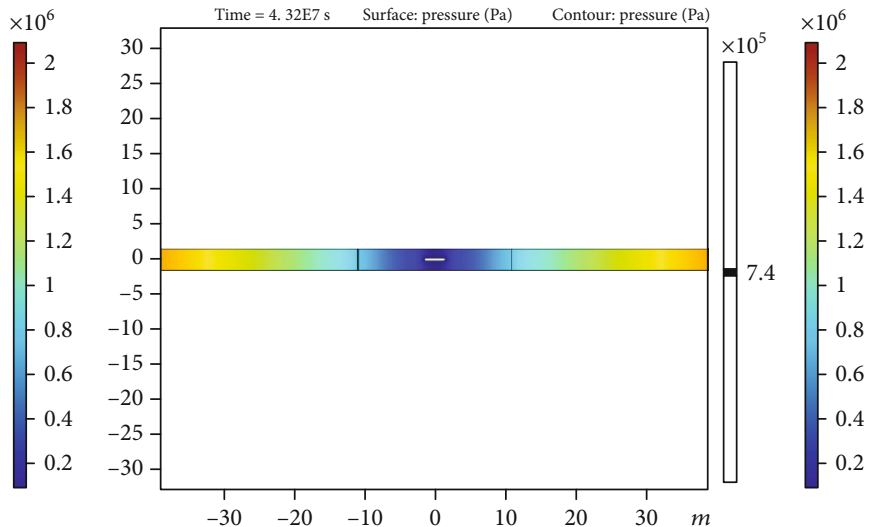

(d)

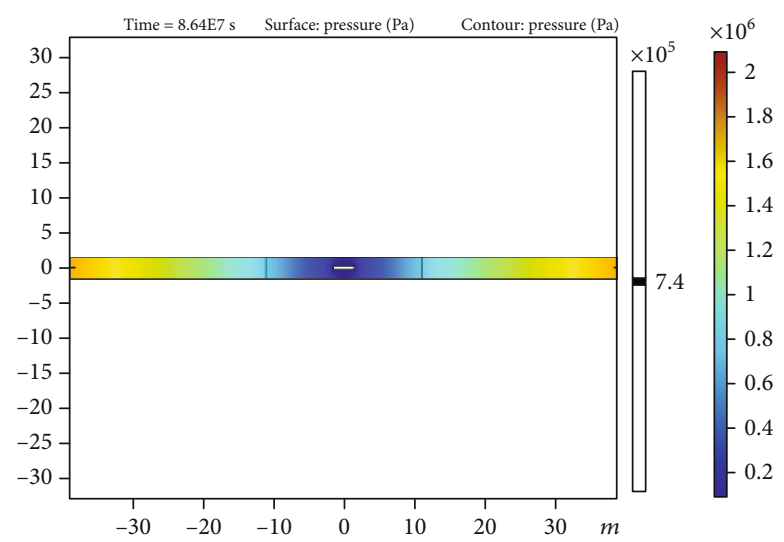

(e)

Figure 8: Methane pressure after different extraction times: (a) 1 day, (b) 50 days, (c) 300 days, (d) 500 days, and (e) 1000 days.

seam depth to $400,600,800,1000$, and $1200 \mathrm{~m}$ to determine the effective radius after high-pressure water jet slotting. Figure 10 shows that the effective radius of methane extraction decreases linearly with increasing coal seam depth. Increasing coal seam burial depth can increase the effective stress of the coal, which exponentially decreases the coal seam permeability. Deeper coal seams are also associated with higher temperatures, which further expand the coal matrix. Because the coal seam temperature is hard to change artificially, the investigation of burial depth is more appropri- ate than temperature [45]. The restrained coal seam in the horizontal and vertical directions leads to a decrease of pores and fractures, which consequentially reduces the permeability.

4.4. Influence of Slot Radius. With regard to the high-pressure water jet slotting characteristics and coal mechanical parameters, we analyzed slot radii of $1,1.5,2.5$, and $3 \mathrm{~m}$. As illustrated in Figure 11, the effective radius of methane extraction increases linearly with increasing slot radius with 


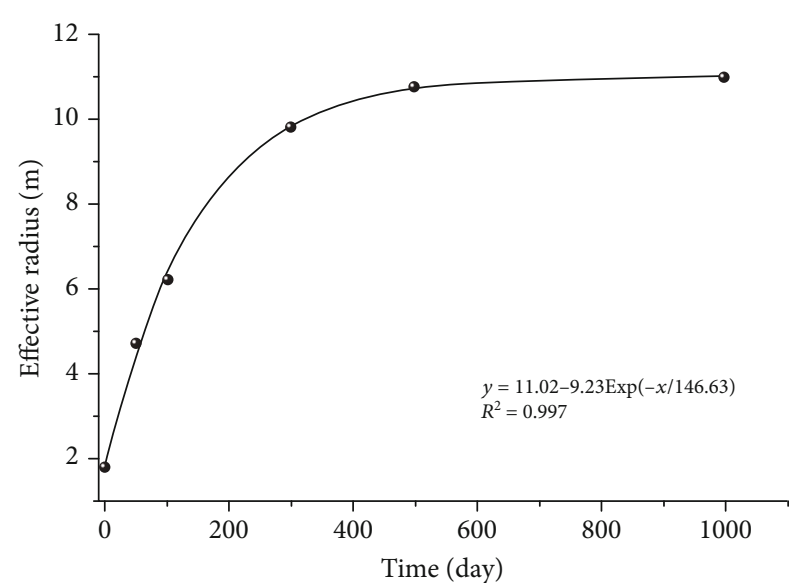

FIGURE 9: Relationship between extraction time and effective radius.

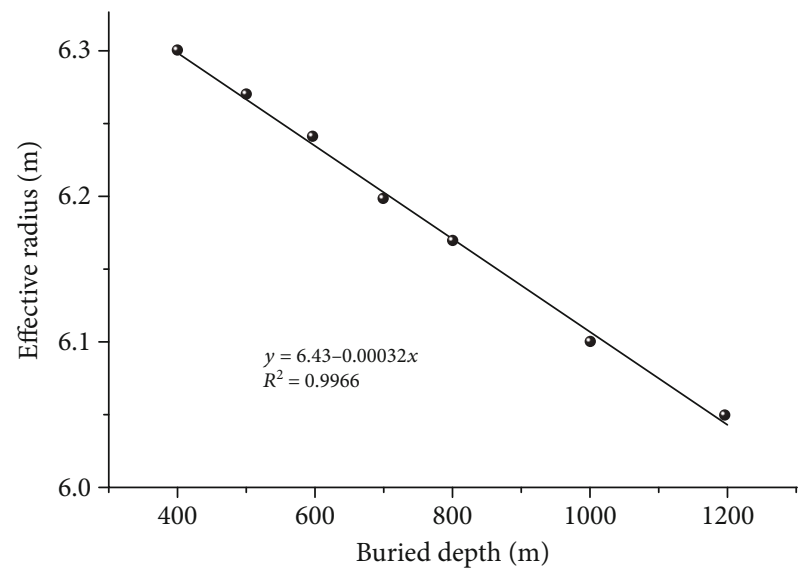

Figure 10: Relationship between coal burial depth and effective radius.

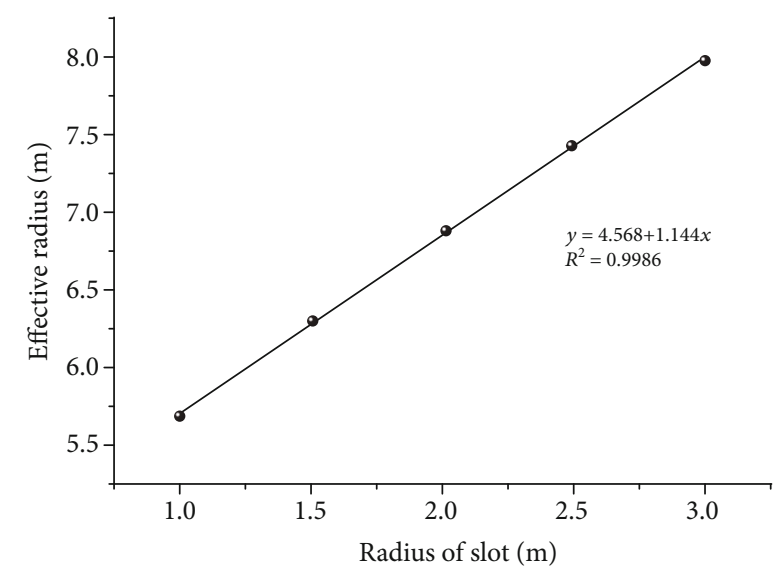

FIGURE 11: Relationship between slot radius and effective radius.

a slope of 1.144, which demonstrates that slotting not only enlarges the diameter of caves in coal seams but also varies the stress distribution and porosity $[46,47]$ around the caves and improves coal seam permeability. However, an improvement of slotted radius is challenging for pumps and pipelines.

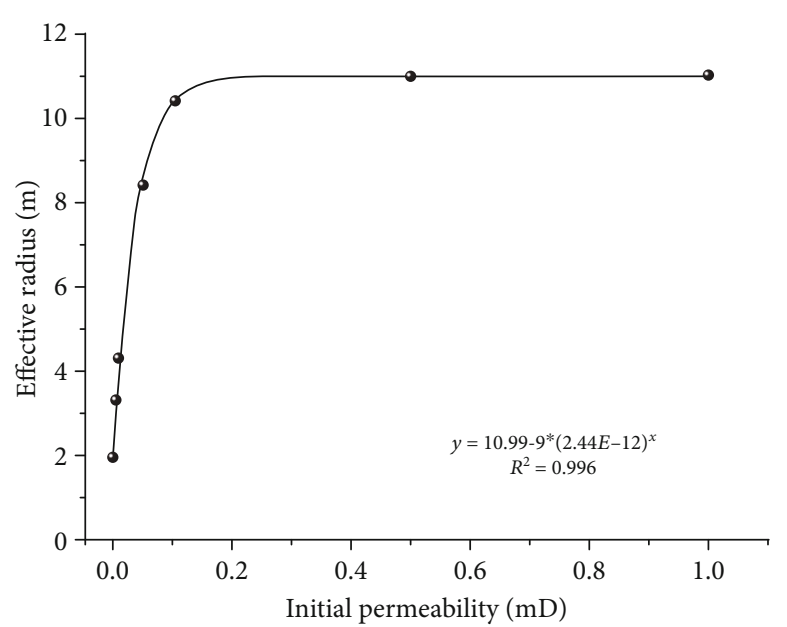

FIGURE 12: Relationship between initial permeability and effective radius $\left(1 \mathrm{mD}=1 \times 10^{-17} \mathrm{~m}^{2}\right)$.

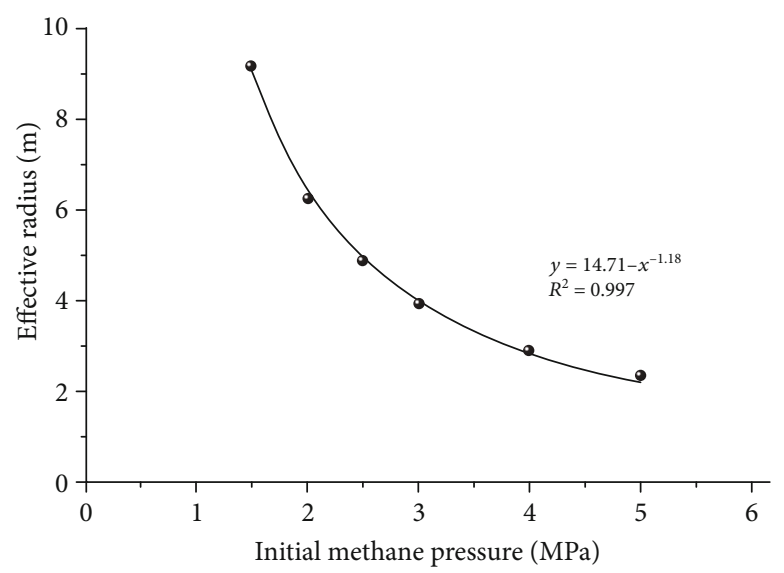

FIGURE 13: Relationship between methane pressure and effective radius.

4.5. Influence of Initial Permeability. Figure 12 shows an exponential relationship between the effective radius of methane extraction and initial coal seam permeability. The effective radius increases from 1.94 to $8.43 \mathrm{~m}$ after 100 days of extraction when the initial permeability of coal seam increases from 0.001 to $0.05 \mathrm{mD}$. Additionally, a slight increase of coal seam permeability can strongly enhance the effective radius of methane extraction when the initial permeability is $<0.1 \mathrm{mD}$. During practical methane extraction in low-permeability coal seams, high-pressure water jet slotting, hydraulic fracturing, protective layer mining, and presplitting blasting can be applied to improve coal seam permeability and reduce extraction time.

4.6. Influence of the Initial Methane Pressure. Figure 13 shows the correlation between initial methane pressure and effective radius of methane extraction. The effective radius decreases following a power function with increasing initial methane pressure. Higher initial methane pressure can linearly improve the pressure gradient, which promotes methane flow by Darcy's law (Equation (1)). The elevated methane 


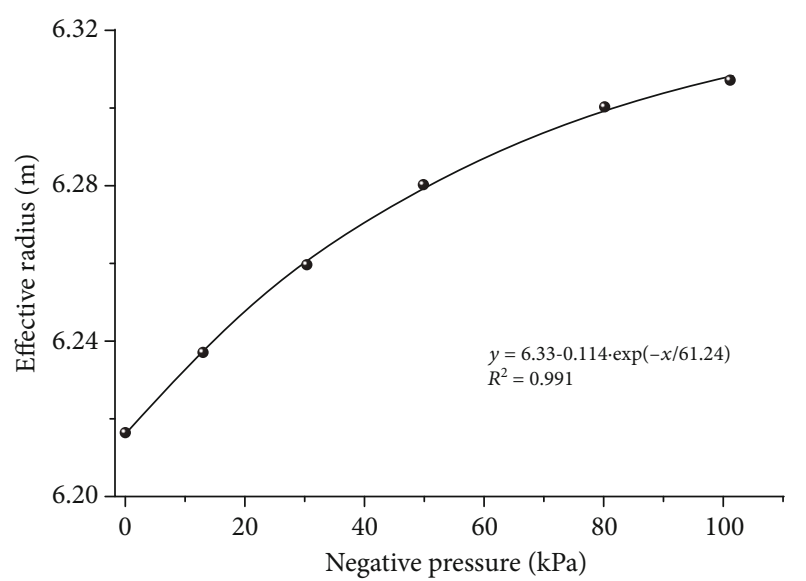

Figure 14: Correlation between negative pressure and effective radius.

pressure also enhances the amount of methane adsorbed via the Langmuir function, which leads to adsorption-induced swelling in the coal matrix and shrinks the tunnels for methane flow. During the methane extraction, the rapidly decreasing methane pressure increases the effective stress (ground stress minus the methane pressure) of the coal seams, which exponentially reduces the permeability. Hence, the predominant effect of effective stress variation largely retards methane extraction. Coal seams with higher initial methane pressure not only introduce a high risk of coal and methane outburst but also complicate methane drainage. Figure 14 shows that the effective radius of methane extraction slightly increases from $6.22 \mathrm{~m}$ for spontaneous flow to $6.31 \mathrm{~m}$ when the pipelines are under an absolute vacuum of $101 \mathrm{kPa}$ (negative pressure).

\section{Conclusions}

We used a fully-coupled thermohydromechanical model to simulate methane extraction after high-pressure water jet slotting and conducted field measurements to confirm the model reliability and validity. We compare our results with a traditional borehole and demonstrate the influence of extraction time, coal burial depth, slot dimensions, initial permeability, and initial coal seam pressure. The conclusions are summarized here.

(1) The effective radius in the K10 coal seam in the Zhongliangshan coal mine reached $4 \mathrm{~m}$ after 16 days of methane extraction and $5 \mathrm{~m}$ after 80 days. The results are in good agreement with the steady flow model and THM coupling model simulation

(2) Compared with a traditional borehole, a slotted borehole can increase the effective radius by a factor of 1.94 after 100 days of methane extraction

(3) The extraction time largely enhances the effect radius up until $\sim 350$ days of methane production. Increasing coal seam burial depth is associated with a linear decrease of effective radius, and the effective radius increases linearly with slot radius
(4) Permeability exponentially increases the effective radius of methane extraction, especially when the initial permeability of coal seam increases from 0.001 to $0.05 \mathrm{mD}$. The effective radius is reduced following a power function with increasing initial methane pressure. The influence of negative pressure on the effective radius is negligible

\section{Data Availability}

The data used to support the findings of this study are available from the corresponding author upon request.

\section{Conflicts of Interest}

The authors declare no competing financial interest.

\section{Acknowledgments}

This work is funded by the National Natural Science Foundation of China (grant no. 51974042) and the QianJiaoHe KY $\mathrm{Zi}$ [2019]073. The first author would like to thank the China Scholarship Council (no. 201406050029) for financial support.

\section{References}

[1] L. Yuan, "Theories and techniques of coal bed methane control in China," Journal of Rock Mechanics and Geotechnical Engineering, vol. 3, no. 4, pp. 343-351, 2011.

[2] S. Tao, S. Chen, and Z. Pan, "Current status, challenges, and policy suggestions for coalbed methane industry development in China: a review," Energy Science \& Engineering, vol. 7, no. 4, pp. 1059-1074, 2019.

[3] UNECE - United Nations Economic Commission for Europe (Methane to Markets Partnership), Best Practice Guidance for Effective Methane Drainage and Use in Coal Mines. ECE Energy Ser. No. 31, United Nations Publications, 2010.

[4] L. Wang and Y. P. Cheng, "Drainage and utilization of Chinese coal mine methane with a coal-methane co- exploitation model: analysis and projections," Resources Policy, vol. 37, no. 3, pp. 315-321, 2012.

[5] B. Li, J. Zhang, J. Wei, and Q. Zhang, "Preparation and sealing performance of a new coal dust polymer composite sealing material," Advances in Materials Science and Engineering, vol. 2018, Article ID 8480913, 10 pages, 2018.

[6] Z. Zhang, D. Yan, X. Zhuang et al., "Hydrogeochemistry signatures of produced waters associated with coalbed methane production in the southern Junggar Basin, NW China," Environmental Science and Pollution Research, vol. 26, no. 31, pp. 31956-31980, 2019.

[7] H. Wen, X. Cheng, J. Chen et al., "Micro-pilot test for optimized pre-extraction boreholes and enhanced coalbed methane recovery by injection of liquid carbon dioxide in the Sangshuping coal mine," Process Safety and Environment Protection, vol. 136, pp. 39-48, 2020.

[8] Z. Luo, D. Li, B. Su, S. Zhang, and J. Deng, "On the time coupling analysis of explosion pressure and intermediate generation for multiple flammable gases," Energy, vol. 198, article 117329, 2020. 
[9] B. Su, Z. Luo, T. Wang, J. Zhang, and F. Cheng, "Experimental and principal component analysis studies on minimum oxygen concentration of methane explosion," International Journal of Hydrogen Energy, vol. 45, no. 21, pp. 12225-12235, 2020.

[10] T. Wang, Z. Luo, H. Wen et al., "Flammability limit behavior of methane with the addition of gaseous fuel at various relative humidities," Process Safety and Environment Protection, vol. 140, pp. 178-189, 2020.

[11] Z. Luo, R. Li, T. Wang et al., "Explosion pressure and flame characteristics of $\mathrm{CO} / \mathrm{CH}_{4} /$ air mixtures at elevated initial temperatures," Fuel, vol. 268, article 117377, 2020.

[12] Y. Lu, Y. Liu, X. Li, and Y. Kang, "A new method of drilling long boreholes in low permeability coal by improving its permeability," International Journal of Coal Geology, vol. 84, no. 2, pp. 94-102, 2010.

[13] C. Liu, B. Xia, and Y. Lu, "Coalbed methane extraction using the self-oscillating water jet slotting method," Energies, vol. 11, no. 4, p. 897, 2018.

[14] Y. Lu, S. Xiao, Z. Ge, Z. Zhou, Y. Ling, and L. Wang, "Experimental study on rock-breaking performance of water jets generated by self-rotatory bit and rock failure mechanism," Powder Technology, vol. 346, pp. 203-216, 2019.

[15] B. Lin and C. Shen, "Coal permeability-improving mechanism of multilevel slotting by water jet and application in coal mine gas extraction," Environment and Earth Science, vol. 73, no. 10, pp. 5975-5986, 2015.

[16] T. Lu, H. Yu, T. Zhou, J. Mao, and B. Guo, "Improvement of methane drainage in high gassy coal seam using waterjet technique," International Journal of Coal Geology, vol. 79, no. 1-2, pp. 40-48, 2009.

[17] Y. Lu, J. Tang, Z. Ge, B. Xia, and Y. Liu, "Hard rock drilling technique with abrasive water jet assistance," International Journal of Rock Mechanics and Mining Sciences, vol. 60, pp. 47-56, 2013.

[18] L. Bai-quan, L. Ting, Z. Quan-le, Z. Chuan-jie, Y. Fa-zhi, and Z. Zhen, "Crack propagation patterns and energy evolution rules of coal within slotting disturbed zone under various lateral pressure coefficients," Arabian Journal of Geosciences, vol. 8, no. 9, pp. 6643-6654, 2015.

[19] Y. Li, D. Tang, H. Xu, Y. Meng, and J. Li, "Experimental research on coal permeability: the roles of effective stress and gas slippage," Journal of Natural Gas Science and Engineering, vol. 21, pp. 481-488, 2014.

[20] X. Cui and R. M. Bustin, "Volumetric strain associated with methane desorption and its impact on coalbed gas production from deep coal seams," American Association of Petroleum Geologists Bulletin, vol. 89, no. 9, pp. 1181-1202, 2005.

[21] H. Wang, B. Xia, Y. Lu, Z. Ge, and J. Tang, "Experimental study on sonic vibrating effects of cavitation water jets and its promotion effects on coalbed methane desorption," Fuel, vol. 185, pp. 468-477, 2016

[22] F. Hao, M. Liu, and W. Zuo, "Coal and gas outburst prevention technology and management system for Chinese coal mines: a review," in Mine Planning and Equipment Selection, pp. 581600, Springer, 2014.

[23] Z. Ge, X. Mei, Y. Jia, Y. Lu, and B. Xia, "Influence radius of slotted borehole drainage by high pressure water jet," Caikuang yu Anquan Gongcheng Xuebao, vol. 31, no. 4, p. 65, 2014.

[24] X. Heping, W. Jinhua, S. Baohong et al., "New idea of coal mining: scientific mining and sustainable mining capacity,"
Journal of China Coal Society, vol. 37, no. 7, pp. 1069-1079, 2012.

[25] M. Pillalamarry, S. Harpalani, and S. Liu, "Gas diffusion behavior of coal and its impact on production from coalbed methane reservoirs," International Journal of Coal Geology, vol. 86, no. 4, pp. 342-348, 2011.

[26] M. B. Kirkham, Principles of Soil and Plant Water Relations, Academic Press, 2nd edition, 2014.

[27] Ф. И. Котяхов, Основы Физики Нефтяного Пласта, Гос. научнотехн. Изд-во нефтяной и горно-топливной литры, 1956.

[28] G. Hong-yu and S. Xian-bo, “An experimental measurement of the threshold pressure gradient of coal reservoirs and its significance," Natural Gas Industry, vol. 30, no. 6, pp. 52-54, 2010.

[29] L. Jing, C. F. Tsang, and O. Stephansson, "DECOVALEX-an international co-operative research project on mathematical models of coupled THM processes for safety analysis of radioactive waste repositories," International Journal of Rock Mechanics and Mining Sciences, vol. 32, no. 5, pp. 389-398, 1995.

[30] Z. Chen, J. Liu, D. Elsworth, L. D. Connell, and Z. Pan, "Impact of $\mathrm{CO}_{2}$ injection and differential deformation on $\mathrm{CO}_{2}$ Injectivity under in-situ stress conditions," International Journal of Coal Geology, vol. 81, no. 2, pp. 97-108, 2010.

[31] Y. Wu, J. Liu, D. Elsworth, H. Siriwardane, and X. Miao, "Evolution of coal permeability: contribution of heterogeneous swelling processes," International Journal of Coal Geology, vol. 88, no. 2-3, pp. 152-162, 2011.

[32] N. Fan, J. Wang, C. Deng, Y. Fan, Y. Mu, and T. Wang, "Numerical study on enhancing coalbed methane recovery by injecting $\mathrm{N}_{2} / \mathrm{CO}_{2}$ mixtures and its geological significance," Energy Science \& Engineering, vol. 8, no. 4, pp. 1104-1119, 2020.

[33] H. Qu, J. Liu, Z. Chen et al., "Complex evolution of coal permeability during $\mathrm{CO}_{2}$ injection under variable temperatures," International Journal of Greenhouse Gas Control, vol. 9, pp. 281-293, 2012.

[34] I. Langmuir, "The adsorption of gases on plane surfaces of glass, mica and platinum," Journal of the American Chemical Society, vol. 40, no. 9, pp. 1361-1403, 1918.

[35] T. Y. Zhang Xiang, "Experimental study on isotherms adsoption of coal on gas under different temperatures," Coal Engineering, vol. 1, no. 4, pp. 87-89, 2011.

[36] W. Zhiyin and L. Yunpeng, Rheological Theory of Rock and Numerical Simulation, Science Press, 2008.

[37] Z. Lai, Experimental studies and simulations on coupled multiphysicses of $\mathrm{CO} 2$ sequestration in deep coal seam, China University of Mining and Technology, 2009.

[38] S.-Y. Wu and W. Zhao, "Analysis of effective stress in adsorbed methane-coal system," Chinese Journal of Rock Mechanics and Engineering, vol. 24, pp. 1674-1678, 2005.

[39] COMSOL, COMSOL Multiphysics 5.3 User Guide. Manual, COMSOL AB, Stockholm, Sweden, 2014.

[40] S. Xiao, Z. Ge, Y. Lu, Z. Zhou, Q. Li, and L. Wang, "Investigation on coal fragmentation by high-velocity water jet in drilling: size distributions and fractal characteristics," Applied Sciences, vol. 8, no. 10, p. 1988, 2018.

[41] J. Pan, Z. Meng, Q. Hou, Y. Ju, and Y. Cao, "Coal strength and Young's modulus related to coal rank, compressional velocity 
and maceral composition," Journal of Structural Geology, vol. 54, pp. 129-135, 2013.

[42] Z. Xiong, C. Song, C. Su et al., "Uniaxial compression creep relaxation and grading of coal samples via tests on the progressive failure characteristics," Geofluids, vol. 2019, Article ID 9069546, 13 pages, 2019.

[43] Y. Q. Tao, J. Xu, M. J. Cheng, S. C. Li, and S. J. Peng, “Theoretical analysis and experimental study on permeability of gasbearing coa," Chinese Journal of Rock Mechanics and Engineering, vol. 28, pp. 3364-3370, 2009.

[44] B. Leśniak, L. Slupik, and G. Jakubina, "The determination of the specific heat capacity of coal based on literature data," Chemik, vol. 67, no. 6, pp. 560-571, 2013.

[45] F. Gao, Y. Xue, Y. Gao, Z. Zhang, T. Teng, and X. Liang, "Fully coupled thermo-hydro-mechanical model for extraction of coal seam gas with slotted boreholes," Journal of Natural Gas Science and Engineering, vol. 31, pp. 226-235, 2016.

[46] Q. Zou, B. Lin, J. Liang et al., "Variation in the pore structure of coal after hydraulic slotting and gas drainage," Adsorption Science and Technology, vol. 32, no. 8, pp. 647-666, 2014.

[47] Q. ZouLe, B. Q. Lin, T. Liu, X. C. Hu, and C. S. Zheng, "Variations in coalbed gas content, initial gas desorption property and coal strength after drilling-slotting integration technique and gas drainage: insight into pore characteristics," International Journal of Oil, Gas and Coal Technology, vol. 15, no. 3, p. 235, 2017. 